\title{
SIMBOLISME AYAM JAGO DALAM PEMBANGUNAN KULTURAL MASYARAKAT KABUPATEN CIANJUR
}

\author{
Ani Rachmat ${ }^{1}$ dan Agusmanon Yuniadi ${ }^{2}$ \\ 'Program Studi Sastra Rusia, Fakultas Ilmu Budaya, Universitas Padjadjaran \\ ${ }^{2}$ Program Studi Sejarah, Fakultas Ilmu Budaya, Universitas Padjadjaran \\ E-mail: ani.rachmat@unpad.ac.id
}

\begin{abstract}
ABSTRAK. Penelitian ini mengkaji latar kultural dan historis pemaknaan ayam jago dalam kebudayaan Indonesia secara umum, dan kebudayaan Sunda secara khusus. Ayam pelung menjadi fokus kajian karena secara simbolik erat kaitannya dengan masyarakat Kabupaten Cianjur. Metode penelitian yang digunakan adalah Metode Sejarah yang terdiri dari empat tahapan yaitu Heuristik, Kritik, Interpretasi dan Historiografi. Sumber-sumber penelitian ini menggunakan sumber naskah, buku, jurnal, serta sumber lisan berupa wawancara. Ayam jago adalah satwa yang merepresentasikan kekuatan. Dalam kebudayaan Sunda, ayam jago erat kaitannya dengan kisah Ciung Wanara. Kisahnya merepresentasikan kebiasaan masyarakat yang gemar dalam memelihara dan mengadu ayam. Kebiasaan memelihara ayam tergambar pula dalam kebiasaan masyarakat Kabupaten Cianjur terhadap ayam pelung. Ayam pelung yang memiliki suara bagus dimaknai bukan hanya dari sisi ekonomi, tetapi juga dari sisi historis dan kultural. Ayam pelung pun kemudian menjadi simbol pembangunan fisik dan psikis Kabupaten Cianjur. Slogan "Cianjur Jago" mengandung harapan akan terciptanya masyarakat yang "jago" secara positif dalam pembangunan kultural masyarakat Kabupaten Cianjur di masa yang akan datang.
\end{abstract}

Kata kunci: Ayam Jago; Ayam Pelung; Cianjur; Simbolisme

\section{SYMBOLISM OF THE ROOSTER AS THE CULTURAL BUILDING OF CIANJUR REGENCY'S SOCIETY}

\begin{abstract}
The main subject this study is the meaning of the rooster - as cultural and historical field - in Indonesian Cultural and especially in Sundanese Culture. "Ayam Pelung” (a kind of Indonesian Rooster) is object of study because it is relate with symbolic value of Cianjur's society custom. Study emlpoys a Historical Method, which consists of four stage: Heuristic, Critic, Interpretation, Historiography. The study utilize some sources such as Sindanese manuscript, book, journal and oral sources. In the general meaning, rooster represent of the strength. It seen in story of Ciung Wanara, a Sundanese Culture tale. The story show the custom of society who like keep and fight of their rooster. This custom seen in habitual Cianjur's Soceity who delight of Ayam Pelung. Ayam Pelung has beautiful voice as economic profit, cultural and historical value. Then, Ayam Pelung is symbolically become sign of Cities building and philosophically to construct of mentalities peoples. Cianjur Regency's government has slogan "Cianjur Jago" which is contains the hope of positive society in the future.
\end{abstract}

Key words: The Rooster; Ayam Pelung; Cianjur; Symbolism

\section{PENDAHULUAN}

“Tugu Ngaos Mamaos Maenpo akan diganti menjadi Tugu Ayam Pelung dan setiap pukul 04.00 WIB akan berkokok sendiri seperti alarm. Selain itu juga masyarakat tidak hanya tahu ayam pelung saja, namun juga harus mengerti filosofi sejarahnya." (Irvan Rivano Muchtar, Bupati Cianjur) (cianjurkini.com, http://www. cianjurkini.com/, diakses 13 Januari 2017).

"Cianjur Jago". Itulah slogan kota yang sekarang gencar didengungkan bupati Cianjur, Irvan Rivano Muchtar. Booming-nya slogan ini dibarengi pula dengan penampakan wajah kota yang banyak berhiaskan logo kepala ayam berjengger merah. Ayam jago dijadikan simbol yang merepresentasikan identitas kultural masyarakat Cianjur. Filosofinya pun menjadi landasan bagi pembangunan kota dan masyarakat Cianjur secara umum.

Simbol wilayah menjadi hal yang diutamakan pada masa pembangunan sekarang ini. Setiap wilayah, baik kota, kabupaten, provinsi, maupun negara, perlu memiliki identitas khas dan unik yang membedakannya dengan wilayah lain. Pembangunan ekonomi khususnya pariwisata menjadi alasan utama yang membuat setiap wilayah "berlomba-lomba" mempercantik kotanya dengan pembangunan fisik dan ragam budayanya. Setiap wilayah berusaha menunjukkan identitasnya berdasarkan elemen fisik (tangible) maupun psikis (intangible), dengan salah satunya memperhatikan nilai-nilai historis serta nilai-nilai lokal setempat sebagai keunikan dan karakteristik sendiri. Kebudayaan merupakan jiwa dan karakter dari suatu wilayah (Amar: 2009).

Kabupaten Cianjur, dengan simbol ayam jagonya merupakan representasi jati diri dan filosofi pembangunan. Simbolisasi ayam jago tak lepas dari pemaknaan terhadap sifat dan karakter ayam jago yang merepresentasikan kegagahan dan kemenangan. Pemaknaan atas wujudnya itulah yang menjadi dasar dan harapan diciptakannya simbol verbal dan simbol monumental di Kabupaten Cianjur. Dalam pembentukannya, identitas kultural memiliki asal dan sejarah yang terus mengalami transformasi. Transformasi ini dipengaruhi oleh sejarah, 
budaya, dan kekuasaan (Hall, 1990: 225). Ayam jago pun tidak semata-mata dipilih sebagai sebuah simbol kultural, tetapi pemaknaan terhadapnya telah mengalami proses historis yang panjang.

Kajian ini akan menjawab permasalahan terkait bagaimana pemaknaan ayam jago dalam masyarakat Indonesia secara umum dan masyarakat Sunda secara khusus, serta bagaimana aktualisasi pemaknaan tersebut dalam masyarakat Kabupaten Cianjur. Satwa kerap kali dijadikan filosofi simbolik mengenai suatu wilayah ataupun suatu hal. Bukan hanya "maung" yang menjadi filosofi Persib Bandung misalnya, ataupun Garuda yang menjadi satwa simbolik nasional. Dalam hal ini lah penelitian ini penting untuk dilakukan untuk melihat bagaimana masyarakat Kabupaten Cianjur meletakkan dasar filosofi kulturalnya pada ayam jago.

\section{METODE}

Penelitian ini menggunakan metode sejarah yang terdiri dari empat tahapan, yakni Heuristik, Kritik, Interpretasi, dan Historiografi. Tahap heuristik ialah kegiatan mencari atau mengumpulkan sumber, baik sumber tertulis maupun sumber lisan. Kajian ini menggunakan beberapa sumber tertulis berupa berupa buku, jurnal, serta naskah seperti Wawacan Sajarah Galuh untuk melihat pemaknaan ayam jago secara historis dalam masyarakat Sunda. Selain itu, digunakan juga naskah perbandingan yaitu Babad Tanah Jawi yang dalam beberapa isinya memuat cerita ayam (Ciung Wanara) di Kerajaan Galuh. Beberapa buku digunakan pula untuk melihat pola kebudayaan terkait pemaknaan ayam jago secara nasional. Dalam penelitian ini, digunakan sumber lisan berupa wawancara yang dilakukan dengan Wakil Bupati Cianjur, Herman Suherman, sebagai sumber primer dalam melihat kebijakan Kabupaten Cianjur terkait simbolisme jago.

Tahap kedua ialah kritik. Sumber yang didapat kemudian melalui tahap kritik eksternal untuk menguji otentisitas sumber, serta tahap kritik internal untuk menguji kredibilitas pembuat sumber. Perbandingan antar sumber dilakukan pula sebagai bentuk mencari fakta yang bisa dipertanggungjawabkan. Hal ini disebut sebagai koroborasi. Koroborasi dilakukan karena dalam mendapatkan fakta sejarah diperlukan suatu dukungan data dari sumber sejarah lain satu atau lebih. Tahap ketiga ialah interpretasi berupa kegiatan menafsirkan fakta-fakta yang ada secara verbal dan faktual hingga dituliskan dalam tahap keempat, yakni historiografi (tahap penulisan).

\section{HASIL DAN PEMBAHASAN}

\section{Ayam Jago: Peliharaan dan Permainan dalam Histo- risitas yang Panjang}

Ayam merupakan hewan yang sangat tidak asing dalam keseharian masyarakat Indonesia. Hewan dengan nama Latin Gallus domesticus ini memiliki nilai fungsional yang beragam, mulai dari hewan penanda pagi (membangunkan manusia), pemuas batin (hobi memelihara ayam), penghasil rupiah (ternak dan sabung ayam), hingga pemenuh nutrisi - bahkan daging ayam dan telur ayam menjadi standar nilai gizi dan kemewahan pangan yang tinggi dalam perspektif masyarakat Indonesia.

Menjadi menarik tatkala ayam disandarkan pada perspektif sejarah, di mana ke-multifungsi-an itu benarbenar tercatat dalam inskripsi-inskripsi dan juga pada tuturan lisan yang turun temurun. Ada garis historis yang panjang dan subjektivitas yang beragam (pada setiap etnisitasnya) terkait pemaknaan manusia terhadap ayam.

Jejak awal perubahan ayam dari makhluk ekologis menjadi makhluk kultural (dimaknai sebagai bagian dari kebudayaan manusia) tidak lepas dari proses domestikasi atau proses penjinakan. Dalam buku Why Did The Chicken Cross The World?: The Epic Saga of the Bird That Powers Civilization, Andrew Lawler menyebutkan bahwa ayam didomestikasi di kawasan Asia Selatan hingga Asia Tenggara sekitar 10.000 tahun lalu (http:// nationalgeographic.co.id, diakses 10 September 2017). Terkait proses domestikasi ini, seorang antropolog Amerika, Phillis Passariello menyebutkan bahwa manusia memiliki subjektivitas dalam memaknai seekor satwa.

"Seekor anjing dapat menjadi teman baik, penyerang yang menakutkan, ataupun (teman) saat makan malam, (semuanya) tergantung konstruksi kultural dan tergantung bagaimana identitas dan kemampuan anjing ditempatkan oleh manusia”. (Passariello, 1999: 12).

Kutipan dari seorang Antropolog Amerika di atas memberi makna bahwa setiap kultur memiliki banyak cara untuk berinteraksi dengan satwa, secara fisik ataupun metaforik. Upaya domestikasi telah menghadirkan berbagai konstruksi kultural, seperti adanya labelling dan treatment terhadap satwa. Anjing yang dilahirkan dalam sifat buas, telah dimaknai sebagai "rekan" sejak periode Mesolitik. Begitupun dengan sapi yang berubah dari keliaran menjadi ternak, kendaraan, hingga simbol religius. Ayam pun pada dasarnya mengalami pemaknaan sebagai simbol kejantanan (jago).

Secara historis, simbolisme terhadap ayam menghadirkan pemaknaan yang sakral sebagai sebuah representasi kekuatan. Ayam menjadi hewan yang sering diadu sebagai simbol kemeriahan kekuasaan. Secara umum,Anthony Reidmenggambarkankebiasaankerajaankerajaan di Asia Tenggara yang sering mengadakan pesta-pesta kerajaan sebagai simbol kemegahan dan kebesaran kerajaan. Segala macam momen - dalam hal ini penobatan raja, perkawinan, penguburan, ritus memasuki usia dewasa, pesta keramaian agama tiap tahun, upacara kesuburan, serta penerimaan tamu luar negeri diperingati dan dilaksanakan dengan arakan-arakan besar dan hiburan umum (Reid, 2014: 200-201). Dalam hiburan itulah terdapat pertunjukan pertarungan satwa sebagai sebuah adu kekuatan. Terkait dengan ayam, pemaknaan 
sebagai kekuatan terlihat pada makna kata sabung dalam adu ayam. Kata sabung yang terdapat dalam inskripsiinskripsi sekitar $922 \mathrm{M}$ secara metaforis diartikan sebagai "pahlawan", "serdadu", "pemenang” (Geertz, 1992: 212).

Ayam memang identik dengan hewan aduan. Hal ini telah dinarasikan Thomas Stamford Raffles dalam The History of Java bahwa sabung ayam dan adu burung puyuh menjadi perlombaan yang sudah sangat umum dilakukan di kalangan masyarakat biasa (Raffels, 2014: 241-243). Sabung ayam menjadi pesta yang sering dilakukan di tiap kota kecil dan pasar (Reid, 2014: 212).

Sumber tertulis tertua menyebutkan bahwa adu sudah dipraktikkan masyarakat Bali sejak abad ke-10, seperti digambarkan dalam Prasasti Sukawana dan Prasasti Batur Abang (Historia, diakses 22 September 2014). Di Jawa, adu ayam telah dilakukan sejak abad ke-11, yang termuat dalam Serat Jago, dengan cerita Cindelaras yang terkenal. Bahkan, kebiasaan ini lebih jauh lagi dilakukan jika merujuk pada folklor Ciung Wanara, dengan latar Kerajaan Galuh pada abad ke-8.

Pemaknaan historis ayam jago pada masyarakat Sunda memang erat sekali mengacu pada kisah Ciung Wanara. Kisah yang termuat dalam Wawacan Sajarah Galuh ini menceritakan suatu perebutan kekuasaan di Kerajaan Galuh. Kisah ini diperkuat pula dengan adanya artefak yang berada di Situs Karangkamulyan, Kabupaten Ciamis. Cerita berawal dari berkuasanya seorang penguasa bernama Ratu Galuh, pendiri Kerajaan Galuh. Setelah mendirikan dan memerintah Kerajaan Galuh, Ratu Galuh memutuskan untuk menjadi pertapa. Ia kemudian menyerahkan singgasana kerajaannya kepada Ki Bondan yang berkedudukan sebagai patih. Ratu Galuh menitipkan kerajaan kepada Ki Bondan dan juga menitipkan cincin soca ludira. Ada sebuah perjanjian jika Ratu Galuh selesai bertapa, maka Ki Bondan harus segera menyerahkan kembali tahtanya. Namun, yang dilakukan $\mathrm{Ki}$ Bondan ialah berkuasa sewenang-wenang. Cincin soca ludira dipakainya dan seketika wajahnya berubah menjadi Ratu Galuh. Perubahan ini tidak diketahui oleh siapapun (Sukaradja dalam Lubis, 2013: 91).

Setelah berkuasa dalam waktu yang lama, di keraton lahir lah seorang bayi laki-laki dari rahim Naganingrum, istri Ratu Galuh. Kelahiran bayi laki-laki itu membuat Ki Bondan khawatir, lalu menyuruh patih kerajaan untuk membunuh bayi tersebut dan membuangnya ke Sungai Citanduy. Sang Patih tidak benar-benar membunuh bayi tersebut, tetapi hanya menghanyutkannya dalam sebuah peti bersama sebutir telur ayam. Bayi laki-laki itu kemudian ditemukan oleh Aki dan Nini Balangantrang, yang merupakan kakek Naganingrum. Setelah ditemukan, mereka kemudian menamakan bayi tersebut dengan nama Ciung Wanara. Sementara itu, telor ayamnya dierami oleh Nagawiru di Gunung Padang. Telur tersebut menetas dan jadilah seekor ayam jantan peliharaan Ciung Wanara (Sukaradja dalam Lubis, 2013: 92).

Di pusat Kerajaan Galuh, Ki Bondan menye- lenggarakan sayembara melalui sabung ayam. Raja Galuh akan menyerahkan setengah wilayah kerajaannya kepada orang yang ayamnya bisa mengalahkan ayam milik raja. Ayam Ki Bondan mampu dikalahkan oleh ayam Ciung Wanara. Namun, Ki Bondan mengingkari janjinya. Untuk mendapatkan haknya, Ciung Wanara membuat penjara dari besi dan meminta Ki Bondan untuk memeriksanya. Ketika Ki Bondan sedang berada di dalam penjara besi, Ciung Wanara menguncinya. Terpenjaralah Ki Bondan dalam kurungan peti itu (Sukaradja dalam Lubis, 2013: 93).

Kisah Ciung Wanara termuat juga dalam Babad

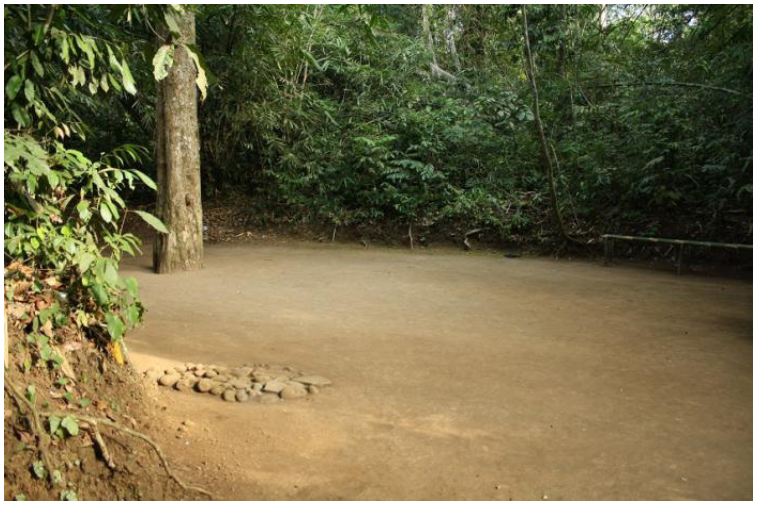

Sumber: Dokumentasi Pribadi 2009

Gambar 1. Penyabungan Ayam di Situs Karangkamulyan

Tanah Jawi, dengan narasi dan penokohan yang sedikit berbeda. Namun, cerita seorang anak terbuang yang kemudian menjadi raja berkat sabung ayam, tetap menjadi narasi utama. Dalam Babad Tanah Jawi, kisah Ciung Wanara menjadi latar belakang terbentuknya Kerajaan Majapahit. Putra mahkota raja yang bernama Raden Sesuruh berperang melawan Ciung Wanara yang bergelar Arya Banyak Wide. Karena kalah, Raden Sesuruh pun pergi ke arah timur, hingga akhirnya mendirikan Kerajaan Majapahit (Olthof, 1941: 14-23).

Di balik kisah Ciung Wanara tersebut terdapat sebuah representasi bahwa memelihara dan mengadu ayam sudah menjadi kebiasaan dan hiburan yang lazim dilakukan. Telah ada suatu pemaknaan "jago" terhadap ayam sebagai hewan adu, di mana pemaknaan tersebut mengantarkan pada adanya perlakuan istimewa berupa treatment terhadap ayam agar menjadi pemenang dalam sebuah pertarungan. Treatment semacam ini digambarkan Clifford Geertz pada kebiasaan orang Bali.

"(mereka) menghabiskan sejumlah besar waktu untuk kesayangan mereka itu, merawat mereka, memberi mereka makan, membicarakan mereka, mencoba mereka satu sama lain, atau hanya menatap mereka dengan kekaguman yang mengasyikkan bercampur lamunan yang melayang-layang...berjongkok bermalas-malasan di bangsal pertemuan atau sepanjang jalan dengan pinggul di bawah, bahu ke depan, seperti berlutut, separuh atau lebih dari mereka memegang seekor jago, mengapitnya di antara kedua pahanya, melambungkannya naik turun dengan lembutnya untuk menguatkan kaki-kakinya, membelai bulu-bulunya dengan sensualitas abstrak, menyentuhkna 
ke jago tetangga untuk membangkitkan gairahnya, menjauhkannya ke pinggangnya dan menenangkannya kembali.." (Geertz, 1992: 213).

Lebih jauh lagi Clifford Geertz menjelaskan bahwa ayam sabungan yang dipelihara di dalam kandang rotan, biasanya sering dipindah-pindahkan untuk menjaga keseimbangan sinar matahari. Memberinya makan jagung dan diet khusus, memasukkan lada merah ke paruh dan dubur untuk meningkatkan gairah, dimandikan dengan air suam-suam kuku, jamu-jamuan, bunga, dan bawang. Ayam pun disikat dengan menggunakan bulu ekor kuda, tajinya diasah, bulunya di rapikan, dan kakikakinya dipijat (Geertz, 1992: 213).

Clifford Geertz pun bicara soal keranjingan jago, di mana seseorang dapat menghabiskan sebagian besar hidupnya untuk jago-jago itu. Hal ini tercermin dalam Kisah Ciung Wanara di mana Ki Bondan sebagai raja Galuh berani mempertaruhkan wilayah kerajaannya gara-gara seekor ayam jago. Secara umum, pemaknaan ayam jago sebagai sebuah peliharaan (hobi) dan juga sebagai satwa aduan telah memiliki benang merah historis yang sangat panjang. Kebiasaan ini tidak bisa hanya disekat dalam satu lokalitas saja, tetapi kebudayaannya me-"nasional". Namun demikian, tetap saja setiap kelokalan memiliki keunikan dan karakteristik yang khas. Pun dengan ayam jago (ayam pelung) dalam masyarakat Cianjur yang telah memiliki tempat sebagai kebiasaan khas yang diwariskan secara turun temurun.

\section{Ayam Pelung Cianjur dan Adopsi Simbolis Pem- bangunan Kultural}

Sahutan kokok ayam yang melengking panjang terdengar di setiap pagi. Terlihat pula beberapa laki-laki berjongkok mengusap-ngusap dan memandikan ayamjago yang besar. Sesekali memegang paruhnya atau memijatmijat tubuhnya. Itulah pemandangan yang sering terlihat di Kecamatan Warungkondang, salah satu kecamatan di Kabupaten Cianjur. Ayam pelung telah menjadi keseharian masyarakat, di mana kepemilikan ayam pelung menjadi sensasi tersendiri. Layaknya merawat anak sendiri, ayam pelung pun mendapat perhatian yang sama terkait kebersihan, kesehatan, dan juga nutrisinya. Pak Agus, salah satu narasumber (sebagai penggiat ayam pelung di Cianjur), menyebutkan bahwa ayam pelung merupakan produk budaya yang khas, di mana tidak ditemukan lagi di kabupaten lain, selain Kabupaten Cianjur (Wawancara Agus pada 7 September 2017). Dengan kata lain, ayam pelung sudah menjadi trendmark, selain juga tentunya tauco yang menjadi panganan khas Kabupaten Cianjur. (Saidah dkk, 2012: 25).

Menurut beberapa penuturan masyarakat, kebiasaan memelihara ayam pelung memang berawal dari Kabupaten Cianjur, namun tidak bisa dipastikan awal mula kebiasaan muncul. Tidak ada bukti tertulis, dan yang hanya ada dua versi tradisi lisan. Menurut versi pertama, permulaan munculnya ayam pelung ada sejak 1850, yang berasal dari Desa Buniasih, salah satu kampung di Kecamatan Warungkondang. Di desa tersebut tinggal seorang kyai sekaligus petani yang bernama Djarkasih atau Mama Acih. Dikisahkan bahwa ia bermimpi bertemu Eyang Suryakencana, sosok yang sangat dipercayai sebagai orang yang sangat sakti. Eyang Suryakencana atau Raden Suryakencana Winata Mangkubumi merupakan seorang putra dari Pangeran Aria Wiratanudatar, seorang pendiri Kabupaten Cianjur (Wawancara Wakil Bupati Cianjur, 8 September 2017). Pada abad ke-19, Kabupaten Cianjur merupakan salah satu kabupaten yang terdapat di Karesidenan Priangan, selain kabupaten Bandung, Sumedang, Parakanmuncang, Limbangan, dan Sukapura (Muhsin, Sosiohumaniora, 2011: 98).

Dalam mimpinya, Kyai Djarkasih diperintahkan untuk pergi ke suatu tempat untuk mengambil seekor ayam. Mimpi itu menjadi kenyataan tatkala Kyai Djarkasih melihat seekor ayam yang berbulu jarang saat ia sedang berada di ladang. Kyai Djarkasih pun kemudian membawa pulang ayam itu dan merawatnya sampai besar. Setelah besar, ayam tersebut memiliki perbedaan dengan ayam kampung lainnya karena suara berkokoknya yang panjang dan mengalun merdu. Ayam ini kemudian dikawinkan dengan ayam biasa, dan melahirkan ayamayam pelung yang ada sekarang.

Menurut versi kedua, ayam pelung Cianjur berawal dari 1940 ketika seorang santri bernama H. Kosim dari Jambudwipa Kecamatan Warung Kondang bertamu kepada gurunya bernama Mama Ajengan Gudang. Saat bertamu, H. Kosim berniat untuk membeli sepasang ayam yang menurutnya memiliki bentuk badan yang berbeda dengan ayam lainnya. Niat tersebut terlaksana dan akhirnya ia membawa ayam tersebut ke Kecamatan Warungkondang untuk dipelihara. Konon, ayam itulah yang menjadi bibit bagi ayam-ayam pelung yang ada di Kabupaten Cianjur.

Kedua versi itu dipercayai oleh masyarakat. Di

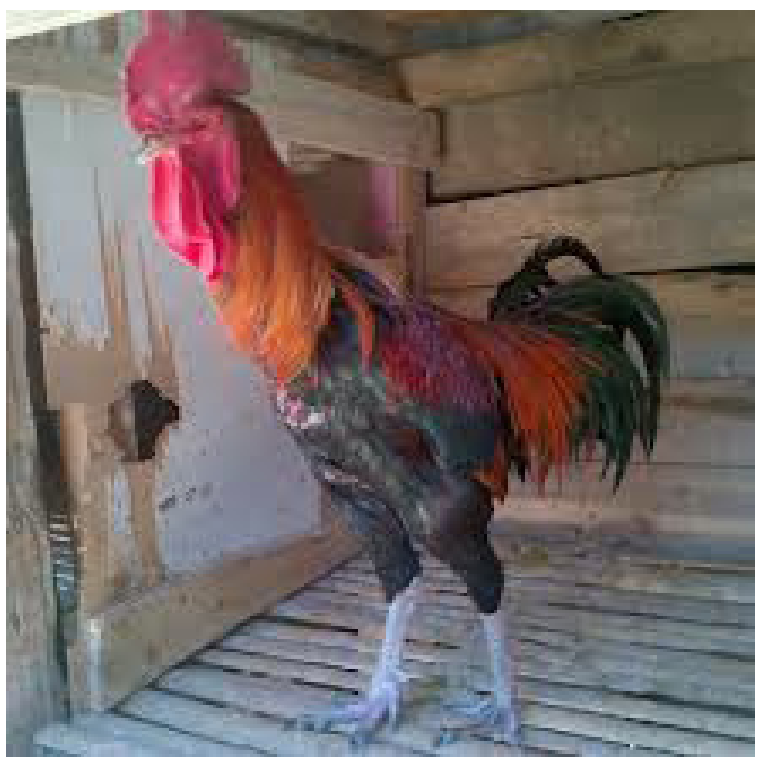

Sumber: Dokumentasi Pribadi 2017

Gambar 2. Ayam Pelung Cianjur 
balik adanya kepercayaan itu, ada sebuah pemaknaan lain oleh masyarakat Cianjur, di mana memelihara ayam pelung dipercaya bisa mendatangkan rezeki, ketentraman, dan kebahagiaan hidup. Tentu manfaat praktisnya menjadi penanda Shalat Subuh bagi masyarakat Cianjur yang mayoritas muslim. Simbolisme seperti ini bisa dikomparasikan dengan pemaknaan masyarakat Jawa terhadap burung perkutut. Burung perkutut - dan juga kuda - menjadi dua dari lima persyaratan yang harus dimiliki laki-laki Jawa. Kelima hal itu adalah turangga (kuda), curiga (senjata), wisma (rumah), wanita (istri), dan kukila (burung perkutut) (Sastroatmodjo, 2006: 11).

Seperti itulah pandangan masyarakat dalam memelihara satwa, dimana terdapat pemaknaan normatif yang disiratkan dalam bahasa simbolik. Pemaknaan simbolik pun kemudian terlihat dalam simbol-simbol kota seperti yang diadopsi Pemerintah Kabupaten Cianjur terhadap kebiasaan memelihara ayam pelung. Jargon "Cianjur Jago" yang didengungkan memang berasal dari filosofi ayam jago atau ayam pelung. Pemaknaannya kemudian meluas bahwa makna "Jago" menyiratkan keunggulan dalam hal positif. Lebih jauh lagi, slogan Jago di sini menurunkan tujuh pilar pembangunan Kabupaten Cianjur yakni, melaksanakan Shalat di awal waktu, Ashar mengaji, menyantuni anak yatim, membiasakan bersedekah, mencintai fakir miskin, penolakan terhadap kemaksiatan, dan pembentukan kampung yang Islami. Kata "Jago" pun oleh masyarakat Kabupaten Cianjur dimaknai sebagai gabungan kata dari Jujur, Agamis, Gigih, Optimis. (Wawancara Wakil Bupati Cianjur, 8 September 2017).

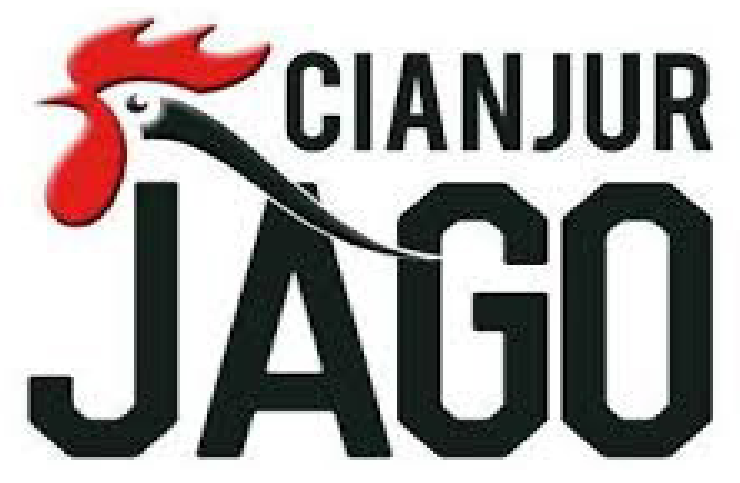

Sumber: cianjurkab.go.id, diakses 7 Agustus 2017

\section{Gambar 3. Slogan Cianjur Jago}

Selain menjadi sebuah jargon, penampakan wajah kota dengan kepala ayam berjengger merah juga sebagai sebuah promosi kebudayaan dan pariwisata Kabupaten Cianjur. Ayam pelung telah diakui sebagai salah satu aset yang harus dilestarikan. Promosi kebudayaan Kabupaten Cianjur salah satunya ialah dengan banyaknya kontes ayam pelung, baik di tingkat lokal, nasional, maupun internasional. Bahkan, ayam pelung Cianjur telah terkenal hingga Jepang, ketika Kaisar Jepang pada 1980an meminta bibit ayam pelung untuk dibudidayakan di Jepang. Namun, demi menjaga keaslian dan kekhasannya, pemerintah Kabupaten Cianjur menolak dan hanya memberi satu ekor ayam pelung saja sebagai bentuk penghormatan (Wawancara Wakil Bupati Cianjur, 8 September 2017).

\section{SIMPULAN}

Ayam jago bukan hanya sekedar makhluk ekologis, tetapi pemaknaan masyarakat terhadapnya telah mengubahnya menjadi "makhluk kultural". Keakraban masyarakat terhadap ayam jago memunculkan pemaknaan tersendiri, sebagai hewan peliharaan dan juga sebagai hewan adu. Ayam pelung sebagai hewan peliharaan dimaknai sebagai warisan kultural yang dipercayai mendatangkan berkah. Masifnya pemeliharaan ayam pelung pada masyarakat Cianjur, membuat pemerintah kabupaten mengadopsinya secara verbal dan visual. Slogan Jago dan juga "ayamisasi” wajah kota merupakan bentuk pemaknaan Pemerintah Kabupaten Cianjur terhadap kekuatan yang dimiliki ayam jago serta pengadopsian terhadap sosoknya secara simbolik menjadi harapan akan terbentuknya masyarakat yang "jago" seperti karakter ayam tersebut. Simbolisasi pada dasarnya menjadi kebiasaan pada setiap masyarakat. Simbolisasi dilakukan pada hal apapun yang akrab dengan masyarakat bersangkutan, baik itu hewan, tumbuhan, ataupun manusia itu sendiri.

\section{DAFTAR PUSTAKA}

Amar, (2009). Identitas Kota, Fenomena dan Permasalahannya, Jurnal ruang, 1, (1), 55-59.

Geertz, C. (1992). Tafsir Kebudayaan. Yogyakarta: Kanisius

Hall, S. (1990). Cultural Identity and Diaspora.” Identity: Community, Culture, Difference. London: Lawrence \& Wishart

Lubis, N.H. (2013). Sejarah Kerajaan Sunda. Bandung: Yayasan Masyarakat Sejarawan Indonesia Cabang Jawa Barat

Muhsin, M. (2011). Dinamika Sosial Ekonomi Priangan Abad ke-19. Sosiohumaniora, 13, (1), 96-107.

Olthof, W.L. (2017). Babad Tanah Jawi. Yogyakarta: Narasi

Passariello, P. (1999). Me and my totem: cross-cultural attitudes towards animals, dalam Francine L. Dolins (ed.), Attitudes to Animals. Cambridge: Cambridge University Press

Raffles, T.S. (2014). The History of Java. Yogyakarta: Narasi

Reid, A. (2014). Asia Tenggara dalam Kurun Niaga 14501680 Jilid I: Tanah di Bawah Angin. Jakarta: Yayasan Pustaka Obor Indonesia

Saidah, Z., Kusno, K. \& Wulandari, E. (2012) Strategi Pemasaran Tauco Cap Biruang di Kabupaten Cianjur. Sosiohumaniora, 14, (1), 24-37. 
Sastroatmodjo. S. (2006). Citra Diri Orang Jawa. Yogyakarta: Narasi

Sukarja, D. (2002). Inventarisasi dan Dokumentasi Sumber Sejarah Galuh Ciamis. Jakarta: Katalog Perpustakaan Nasional RI

Wawancara Agus (Ketua Perkumpulan Pegiat Ayam Pelung Cianjur), 7 September 2017

Wawancara Wakil Bupati Cianjur, 8 September 2017

Hanggoro, T.H. (2014). Perang Ayam, Historia, https:// historia.id/kuno/articles/perang-ayam-DrdkP, diakses 22 September 2014
Radar Cianjur. (2017) Tugu Ngaos Mamaos Maenpo di Cianjur Akan Diganti Ayam Pelung. https:// cianjur.pojoksatu.id/baca/tugu-ngaos-mamaosmaenpo-cianjur-diganti-tugu-ayam-pelung-setuju diakses 13 Januari 2017

Nationalgeographic Ayam. (2017). Berevolusi Mengiringi Peradaban Manusia. http://nationalgeographic. grid.id/read/13296278/ayam-berevolusimengiringi-peradaban-manusia?page $=$ all diakses 10 September 2017, diakses 9 September 2017. 